\title{
The Effectiveness of Prompt and Recast on the Pronunciation of Moroccan EFL Learners: The Case of English Department Students in Sais Faculty
}

Mohamed Benhima ${ }^{1 *}$ and Souad Slaoui ${ }^{2}$

${ }^{12}$ Faculty of Arts and Humanities, Sidi Mohammed Ben Abdellah University, Fes, Morocco

Corresponding Author: Mohamed Benhima, E-mail: benhima01@gmail.com

\section{ARTICLE INFORMATION}

Received: October 12, 2020

Accepted: December 01, 2020

Volume: 2

Issue: 5

DOI: 10.32996/ijels.2020.2.5.4

\section{KEYWORDS}

Corrective Feedback (CF), phonological inter-language, pronunciation, prompt, recast

\section{ABSTRACT}

This study aims to investigate the differential effects of two methods of error correction, namely prompt and recast, on the pronunciation of Moroccan EFL learners. Accordingly, an exploratory observation was conducted to design a test instrument followed by an experimental design wherein thirty English Department students in Sais Faculty in Fes $(n=30)$ were divided into prompt, recast and nofeedback control groups. A pre-test was administered to the three groups, revealing that EFL learners make similar mistakes in the pronunciation of some English sounds due to the lack of correspondence between spelling and pronunciation. Subsequently, the experimental groups received immediate treatment for their pronunciation mistakes. The post-test, as examined by the One-Way Analysis of Variance (ANOVA), revealed a significant difference between the prompt as compared to the other groups.

\section{Introduction}

The accuracy of pronunciation as one of the crucial sub-skills of language learning has long been undermined in the era of the Communicative Approach during the last decades of the twentieth century. Since then, it has been emphasized that fluency and focus on meaning during oral interaction are the ultimate goals of language learning. Hence, classroom instruction should ignore language errors at the level of all language aspects, especially pronunciation (Ellis 2003; Hymes 1972; Prabhu 1987; Truscott 1996). Moreover, the affective theories in second language acquisition further contributed to minimizing the importance of error correction and language forms as they inhibit language learning (Krashen, 1982). However, it has been noticed that many language learners, who were taught by fluency based models, find themselves fluently producing meaningfully-deviant streams of speech sounds due to making errors in phonemes during pronunciation. Such pronunciation inaccuracies lead, in turn, to communication failure, making the assumptions upon which the Communicative Approach was first based fallacious. A refocus on form and accuracy has accordingly been brought to the fore especially at the dawn of the twentieth-first century (VanPatten \& Cadierno, 1993). In the current study, a review of studies on oral corrective feedback will be presented and classified. This will be followed by the statement of the problem, research questions, and significance of the study. Moreover, there will be a description of the participants in the control and experimental groups in addition to the research procedures and measurement tool of the word list reading task on consonants, vowels and stress. Finally, the data will be scored and analyzed by means of one-way ANOVA. The results will be discussed in light of the research questions and hypotheses.

\section{Literature review}

Several were the descriptive and experimental studies that have attempted to investigate the efficacy of corrective feedback in second language acquisition and learning. In general, corrective feedback refers to the response to a student's production or reception of the language in the four language skills and the three language aspects, namely grammar, vocabulary and pronunciation. It is also defined as an indication to the learners that their use of the target language is incorrect (Lightbrown

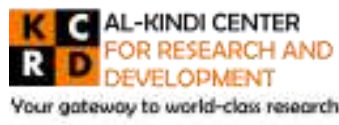

Published by Al-KindiCenter for Research and Development. Copyright (c) the author(s). This is an open access article under CC BY license (https://creativecommons.org/licenses/by/4.0/) 
\& Spada, 1999, p. 171). It is classified into written and oral corrective feedback. The latter involves many types, the chief of which are prompt and recast. Prompt pushes the learner to self-correct through elicitation by wh-questions or fill-in-the-blank. Prompt in pronunciation treatment can be exemplified in the following exchange:

\author{
Student: */It Iz switəbəl/ \\ Teacher: it is ....? (prompts with elicitation) \\ Student: /It Iz su:tabl/ _ (successful uptake)
}

Recast consists of the provision of the correct form or the reformulation of the learner's erroneous utterance without the error. An example of recast is as follows:

$$
\begin{aligned}
& \text { Student: * / ar determain/ ... } \\
& \text { Teacher: you /determIn/ ... } \\
& \text { Student: Yes, I /determIn/ ... }
\end{aligned}
$$

Prompt and recast can be used in oral interaction or even in reading in which the focus is on the development of pronunciation or phonological interlanguage, which is a transitional competence of second or foreign language learners (Corder, 1973; Selinker, 1972). CF studies have been divided into studies that show the ineffectiveness of corrective feedback (Krashen, 1981; Truscott, 1999) and those which prove the effectiveness of error treatment in language learning (Lyster \& Saito, 2010; Mackey \& Goo, 2007; Russell \& Spada, 2006). CF studies were further divided into sub-studies that favor one type of error correction either prompt or recast over the other depending on numerous variables such as language aspect, language proficiency, attitudes, age and instructional context, among others. In general, the various descriptive and experimental studies can be grouped into three categories, namely the non-effectiveness of corrective feedback studies, the effectiveness of prompt studies and the effectiveness of recast studies.

\title{
2.1 The non-effectiveness of corrective feedback studies
}

Few were the studies that found negative or no significant effect of corrective feedback on language acquisition and learning. The first most famous view was held by Krashen (1981), who in his study of second language acquisition, advocated that error correction raises learners' affective filter which blocks the development of the acquired system. The second series of studies were conducted by Truscott $(1996,1999,2007)$ who raised a case, in response to Ferris, against error correction and its disutility in inter-language restructuring or grammar acquisition. Even some educationalists of counseling learning and affective domains like Curran and Lozanov argued that error correction has detrimental effects on learners as it inhibits them and negatively affects their attitude, motivation and confidence in language learning. To correct or not to correct language errors has, thus, remained one of the contentious questions in language pedagogy.

\subsection{The effectiveness of prompt studies}

The effectiveness of prompts as an output-pushing error correction strategy has been attested by several recent empirical studies. For example, Ammar \& Spada (2006) in a quasi-experimental study concluded that prompts are more effective than recasts on the learning of third-person possessive due to the provision of negative evidence, i.e. pushing learners to reformulate the erroneous utterance. Another quasi-experimental study by Jafarpour and Hashemian (2013) found out that prompts are more statistically significant than recasts and no-feedback in terms of third-person singular marker among Persian learners. In the same vein, Yang and Lyster (2010) conducted an experiment on almost 70 Chinese college students to test the effectiveness of prompts and recasts on the misuse of simple past. They concluded that prompts are more effective than recasts in such corrections due to their learner-centered nature in that learners become active in the process of correction.

\subsection{The effectiveness of recast studies}

The efficacy of recasts as an implicit input-providing error correction technique has been proven in a vast number of studies (Doughty, 1994; Long, Inagaki \& Ortega, 1998; Mackey, 1999;). Since recasts provide learners with positive evidence, they were found to help learners notice the difference between their original utterance and the target-like reformulation (Schmidt, 1990, 2001; Long, 1996). Moreover, recasts were used as form-focused techniques that draw students' attention to form during communicative and meaning-based activities (Long, 1991; VanPatten, 1990, 2004). Finally, recasts are found to be widely used pedagogical practices in language classrooms (e.g., Doughty, 1994; Lyster, 2004; Lyster \& Ranta, 1997; Panova \& Lyster, 2002; 
Sheen, 2004, 2006).

In short, to correct or not to correct errors has long been an intriguing question in second language acquisition and research. While some researchers have negated the effectiveness of error correction in improving language accuracy (Krashen, 1981; Truscott, 1996), others have found some evidence on its usefulness in language pedagogy (Ellis, 2006; Lyster \& Ranta, 1997). Research in favor of corrective feedback has remained divided mainly into prompts and recasts. While there are studies that favor prompts, there are other studies that favor recasts in generating the correct uptake and appropriate repair by learners depending on several variables.

However, a common feature among these studies is that all of them focused on grammar and morphology, and lip service has been paid to pronunciation and phonology.

\section{Method}

\subsection{Statement of the problem}

The accuracy of pronunciation has long been undermined in the communicative era. It was argued by the communicative advocates that focus on language accuracy will raise students' anxiety and interrupt the flow of communication. Hence, errors should be ignored in communicative classrooms where the focus is primarily laid on meaning and interaction. However, it has been noticed that learners who have fossilization in their phonological inter-language frequently miscommunicate in the target language when they interact in real-life contexts. Thus, the current study purports to investigate whether error correction has a constructive or detrimental effect on the accuracy of pronunciation and which corrective techniques are more effective than others.

\subsection{Research questions}

The current study aims to answer the following research questions:

Q.1. To what extent does corrective feedback impact pronunciation accuracy?

Q.2. Is it prompt or recast that is the most effective error correction technique on pronunciation accuracy?

\subsection{Hypotheses}

The current study is premised on null and alternative hypotheses which are stated as follows:

H0: There is no significant differential effect of prompt, recast and no-feedback on the pronunciation accuracy of Moroccan EFL learners.

$\mathrm{H} 1$ : There is a significant differential effect of prompts and recasts on the pronunciation accuracy of Moroccan EFL learners.

\subsection{Significance}

The knowledge of the differential effectiveness of prompt and recast on pronunciation is significant theoretically and pedagogically. Theoretically, insights can be gained on phonological interlanguage restructuring and motor- skills. Moreover, this study is an implicit verification of the relation of pronunciation with some theoretical constructs in second language acquisition, such as input, noticing, intake, and output. Pedagogically, the findings of this study may illuminate teachers as to the ways of focusing on the form which occurs during meaning-based negotiation. More particularly, teachers will be aware of the most effective error treatment strategies and the skills to implement or test them in their language classrooms through action-oriented research.

\subsection{Participants}

The participants in a study are defined as the set of individuals chosen from a target population. Since it is quite unpractical to study the entire population, several sampling techniques have been suggested to select a representative and generalizable sample from the whole population or universe. These techniques fall into two broad categories, viz. non-probability and probability sampling (Kothari, 2004). A combination of different sampling designs is also possible through what is called mixedsampling approaches (Moser \& Stuart, 1953).

In the current study, six observation sessions have been conducted with a sample of six teachers mostly lecturing and rarely interacting with their students in the amphitheaters of the English department undergraduate program in Sidi Mohamed Ben Abdellah University in Fes, a city in the middle of Morocco. The observed lectures are of the culture, composition, grammar 
and media studies modules. The observations were done for the sake of exploring the cases of mispronunciation and the sounds with which undergraduate learners have more difficulties. Accordingly, a word list reading task was designed and addressed to a subsample of thirty students who were randomly selected from the general sample for the experimental treatment. In general, the background of the student participants in the current study is displayed below.

Table 1: The demographic profile of the participants in the experiment

\begin{tabular}{cccccc}
\hline \multirow{2}{*}{ Gender and age } & Gender & & \multicolumn{2}{c}{ Age } \\
& Male & Female & $18-20$ & $21-25$ & $26-30$ \\
\hline $\mathrm{N}$ & 12 & 18 & 10 & 19 & 1 \\
\hline
\end{tabular}

Concerning the demographic information of the participants in the current study, Table 1 describes the randomly chosen sample in terms of gender and age. With respect to age, the majority of students are aged between 21 and 25 . The respondents of the current study have surpassed the age which is set by the Critical Period Hypothesis in 2 years. With respect to gender, the majority of the participants (18) are females compared to (12) males. Gender and age remain extraneous variables in the current study.

\subsection{Procedures}

The current study makes use of a true-experimental research design which goes hand in hand with the research objectives and hypotheses. In this design, a sample or a subsample which consists of English Department students in Sidi Mohamed Ben Abdellah University is divided into an experimental group and a control group. While the control group receives no treatment, the experimental group is the subject of treatment and intervention to test the effectiveness of a certain intervention strategy. The current study aims to investigate the impact of prompt and recast on the pronunciation of Moroccan EFL learners by conducting pre-tests, immediate treatment sessions and post-tests on a control group with no corrective feedback and two experimental groups with prompt and recast corrective feedback. The students were randomly recruited.

First of all, the participants of the study had to take a pre-test to ensure a high degree of homogeneity between and within experimental and control groups. Thus, the randomly chosen sample from a population of students sat for a pre-test. The rationale behind the pre-test is to control for confounding or extraneous variables in that the change in the behavior of participants is due to the impact of treatment, not other things.

Secondly, the participants were divided into two experimental groups with two methods of treatment and one control group with no treatment condition. While the two experimental groups were divided into prompt and recast groups, the control group received no treatment or placebo. The participants were asked to pronounce some sounds in a word list test (see Appendix A). The experimental groups immediately received one shoot of treatment due to the limitations of time to avoid participant attrition.

Finally, the two experimental groups and the control group sat for the post-test. The results generated from which were scored and compared using the Statistical Package of Social Science (SPSS) 23. Furthermore, the statistical test of Analysis of Variance (ANOVA) was run on the data to verify whether the difference in scores between groups or within groups is either by chance or by statistical significance. The Shapiro-Wilk test confirmed that the data of the three groups are normally distributed. Levene's test was used to check the homogeneity of variance. Levene's test allowed us to see that the variances between groups do not significantly different.

\section{Results}

Students were asked to read a word-list consisting of 60 items related to consonants, vowels and stress. 30 students took part in the experiment. While 20 students were randomly assigned to the prompt and recast group with a proportion of 10 students per each, 10 students were taken as a control group. The data was tape-recorded and scored by assigning one for correct pronunciation and zero for an incorrect pronunciation. In general, the no corrective feedback group repeated the same mistake with few self-correction attempts, whereas the experimental groups showed some differences in the post-test in that the prompt group made fewer pronunciation mistakes than the recast group. For further statistical validation, the comparison in the mean scores between the prompt and recast groups has been statistically calculated by an ANOVA test. The latter, as was 
explained before, tests whether the difference between the two groups occurs by chance or is statistically significant. The table below depicts the degree of significance:

Table 2: The comparison between the prompt and the recast groups

\begin{tabular}{llllll}
\hline & Sum of Squares $\mathrm{df}$ & Mean Square & $\mathrm{F}$ & Sig. \\
\hline Between Groups & 4062.067 & 2 & 2031.033 & 165.523 & .000 \\
Within Groups & 331.300 & 27 & 12.270 & & \\
Total & 4393.367 & 29 & & & \\
\hline
\end{tabular}

The results of one-way ANOVA on the post-test showed the difference between groups is statistically significant. The P-value was set at .05. Thus, the more the sig. level is less than .05 , the more significant are the results. In the case above, the significance level of recast is less than .05 alpha level. Therefore, the generated finding leads to the rejection of the null hypothesis which states that there is no significant difference in treatment methods. This gives rise to the alternative hypothesis. The post hoc Tukey HSD test shows that all three groups significantly differ from each other, with the prompt group having the highest mean followed by the recast and control group.

\section{Discussion}

The pronunciation of English sounds by Moroccan EFL learners is often characterized by many inaccuracies that impair communication. Two corrective strategies have been identified, namely prompts and recasts. While prompts allow the use of many elicitation, repetition and metalinguistic moves, recasts are related merely to giving the correct forms directly. Corrective feedback through prompt and recast has long been proven to be effective in pronunciation error correction. To confirm this, an ANOVA comparison between the means of two groups has shown that the prompt group scored significantly fewer errors than the recast and no-feedback groups. Prompt is effective because learners can produce complex errors, which require many moves, especially metalinguistic cues and repetition. The efficacy of prompt compared to recast as asserted in Ammar and Spada (2006) is manifested in several ways in the current study.

Prompt through meta-linguistic cues and recasts allow students to notice the difference between their erroneous formulation of consonants and correct formulation for self-correction in similar cases. For instance, students substitute [k] for [t $\mathrm{t}]$ as in "chorus", "archive" and "anarchy" being pronounced as [t $\mathrm{f} \supset$ :rəs], [a:[Iv] and [anər[I], respectively. Moreover, students oftentimes pronounce silent letters as in pronouncing "knock", "sandwich" and "solemn" as [knpk], [spləmn] and [sændwid3]. In such cases, metalinguistic cues will lead students to notice the gap between their ill-formed form and correct forms to ultimately produce correct forms.

The efficiency of prompt and recast in comparison to no-feedback in pronunciation can also be attested in the pronunciation of different vowels. Moroccan EFL learners make more mistakes in vowels, especially monophthongs and diphthongs. For instance, students mispronounce the words "iterate", "live" and "determine" as [artərert], [larv], and [dr'tz:marn]. Furthermore, students have difficulties with vowel length in that they pronounce sheet, seat, and beat as [Jit], [sit] and [bIt], respectively. Such phonemic errors are more likely to result in miscommunication and embarrassment if they are not corrected.

In addition to the efficiency of corrective feedback in segmental phonology, it plays a crucial role in the suprasegmental aspects of stress, especially of verbs and nouns. Moroccan EFL learners often put stress on the first syllable when pronouncing verbs such as PRESent, COMMent, and EXport. Similarly, they stress the last syllable in nouns like record, conTENT, preSENT. Hence, the corrective intervention in the form of prompt and recast is mandatory in pronunciation mistakes which have a detrimental effect on grammar and syntax, too. The use of corrective feedback in the experiment showed that certain words need to be corrected by both prompt and recast feedback, especially vocalic and suprasegmental features which are subject to complex errors.

In general, corrective feedback in the form of prompt was proven to be more effective than no-feedback and recast in several cases in the conducted study. The first case relates to consonantal sounds such as the substitution of [k] for [t]] as in chorus and the pronunciation of silent letters as in comb and sandwich. The second case is related to vocalic sounds as in the shortening of vowels words such as sheet, beat and seat. The third and last case concerns the suprasegmental feature of stress which is erroneously placed on the first syllable in verbs and last syllables in nouns. Students in the experiment have noticed recast more than prompt in these three pronunciation areas. 


\section{Conclusion}

All in all, the objective of the current study has been to investigate the effectiveness of two methods of error correction, namely prompt and recast, on students' pronunciation in tertiary education. The investigated questions have revolved around whether or not to respond to errors, and which error correction methods are more effective. The current research is an attempt to answer such questions, with special reference to pronunciation accuracy of Moroccan EFL learners at the tertiary level, taking the case of undergraduate English department students in Sidi Mohamed Ben Abdellah University in Fes. It is based on a trueexperimental design. The latter consists of pre-tests, treatments with two common methods of error correction, and immediate post-test to verify the null and alternative hypotheses concerning the differential effects of error correction on phonemic competence in the field of second language acquisition. In this respect, thirty students were randomly assigned to a control group with no treatment and two experimental groups with prompt and recast treatment. One-way ANOVA and Post-hoc Tukey HSD performed on the generated data revealed that students corrected with prompts with metalinguistic cues performed far better than those corrected with recasts and those with no-feedback. This supports the findings on the role of feedback on modified output, noticing, intake, and uptake in second language acquisition. A case in point is about Swains' findings which led her to form the 'comprehensible output hypothesis': input is not sufficient and learners need to be 'pushed' in their output to be able to acquire certain grammatical features. As for the limitations of the study, the effect size and power analysis can be calculated due to the lack of a sampling frame. The results cannot be generalizable. Moreover, randomly choosing students of different ages for a cross-sectional study is more likely to influence the results. Therefore, controlled experiments are highly recommended for future research.

\section{ABOUT THE AUTHORS}

Souad Sloaui is a professor of Linguistics and Gender Studies. She is also the director of the Applied Language Studies and Research in Higher Education Master Program at Sidi Mohammed Ben Abdellah University.

Mohamed Benhima is a secondary school teacher and a doctoral researcher in the Discourse, Creativity and Society Laboratory at Sidi Mohammed Ben Abdellah University. He studied in the Master Program of Applied Language Studies and Research in Higher Education at Sidi Mohammed Ben Abdellah University.

\section{References}

[1] Ammar, A., \& Spada, N. (2006). One size fits all?: Recasts, prompts, and L2 learning. Studies in Second Language Acquisition, 28 (04). DOI: $10.1017 /$ S0272263106060268

[2] Corder, S. P. (1967). The significance of learner's errors. International Review of Applied Linguistics, 5: 4, $161-169$.

[3] Doughty, C. (1994). Fine-tuning of feedback by competent speakers to language learners. In J. Alatis (Ed.), GURT 1993: Strategic interaction and language acquisition (pp. 96-108). Washington D.C.: Georgetown University Press.

[4] Doughty, H. \& Varela, E. (1998). Communicative focus on form. In C. Doughty \& J. Williams (Eds.), Focus on form in classroom second language acquisition (114-138). New York: Cambridge University Press.

[5] Ellis, Rod (2003). Task-based language learning and teaching. Oxford, New York: Oxford Applied Linguistics.

[6] Ellis, R. (2006). Researching the effects of form-focused instruction on L2 acquisition. In K. Bardovi-Harlig \& Z. Dornyei (Eds.), Themes in SLA Research (AILA Review 19, pp. 18-41). Amsterdam: John Benjamins.

[7] Hashemian, M., Mirzaei, A., Mostaghasi, H. (2016). Exploring different oral corrective feedback preferences: Role of intrapersonal and interpersonal intelligences. Research in Applied Linguistics, 7(2), 140-159. doi: 10.22055/rals.2016.12098

[8] Hymes, D. H. (1972). On communicative competence. In J.B. Pride \& J. Holmes (Eds.), Sociolinguistics

[9] (pp. 269-293). London: Penguin.

[10] Jafarpour, A. A., \& Hashemian, M. (2013). Impact of recasts and prompts on the learning of English third-person singular marker by Persian learners of English. International Journal of Foreign Language Teaching and Research, 1(2), 23-36.

[11] Kothari C.R (2004). Research methodology methods and techniques (2nd ed.). New Age International Publisher.

[12] Krashen, S. (1981). Second language acquisition and second language learning. Oxford: Pergamon Press.

[13] Lee, J. (2007). Corrective feedback and learner uptake in English immersion classrooms at the primary level in Korea. 영어교육, 62(4).

[14] Lightbown, P. M., \& Spada, N. (1990). Focus-on-form and corrective feedback in Communicative Language Teaching: Effects on second language acquisition. Studies in Second Language Acquisition, 12, 429-448.

[15] Lightbown, P., \& Spada, N. (1999). How languages are learned (2nd ed.). Oxford: Oxford University Press.

[16] Long, M. H. (1991). Focus on form: A design feature in language teaching methodology. In K. de Bot, D. Coste, R. Ginsberg, \& C. Kramsch (Eds.), Foreign language research in cross-cultural perspectives (pp. 39- 52). Amsterdam/Philadelphia: John Benjamins Publishing Company.

[17] Long, M. H. (1996). The role of the linguistic environment in second language acquisition. In Ritchie, W. \& Bhatia, T. (Eds.), Handbook of second language acquisition: Vol. 2. Second language acquisition (pp. 413-468). San Diego, CA: Academic Press. 
[18] Long, M., Inagaki, S., \& Ortega, L. (1998). The role of implicit negative evidence in SLA: Models and recasts in Japanese and Spanish. Modern Language Journal, 82, 357-371.

[19] Lyster, R. (1998). Negotiation of form, recasts, and explicit correction in relation to error types and learner repair in immersion classrooms. Language Learning, 48, 183-218.

[20] Lyster, R. (2004). Differential effects of prompts and recasts in form-focused instruction.

[21] Studies in Second Language Acquisition, 26, 399-432.

[22] Lyster, R., \& Ranta, L. (1997). Corrective feedback and learner uptake. Studies in Second Language Acquisition, 19, 37-66

[23] Lyster, R. \& Saito, K. (2010). Effects of oral feedback in SLA classroom research: A meta-analysis. Studies in Second Language Acquisition, 32, 265-302

[24] Mackey, A. \& Goo, J. (2007). Interaction research in SLA: A meta-analysis and research synthesis. In A. Mackey (Ed.), Conversational interaction in second language acquisition: A collection of empirical studies, 407-452. Oxford: Oxford University Press.

[25] Moser, C.A. \& A. Stuart. 1953. An experimental study of quota sampling. Journal of the Royal Statistical Society: Series A 116, 349405.

[26] Nassaji, H. (1999). Towards integrating form-focused instruction and communicative interaction in the second language classroom: Some pedagogical possibilities. Canadian Modern Language Review, 55, 385- 402. Doi: 10.3138/cmlr.55.3.386

[27] Nassaji, H. (2007). Elicitation and reformulation and their relationship with learner repair in dyadic interaction. Language Learning, $57,511-548$

[28] Nassaji, H., \& Fotos, S. (2007). Current issues in form-focused instruction. In S. Fotos, \& H. Nassaji (Eds.), Form focused instruction and teacher education: Studies in honor of Rod Ellis (pp. 7-15). Oxford: Oxford University Press.

[29] Nassaji, H. \& Fotos, S. (2011). Teaching Grammar in Second Language Classrooms: integrating form focused instruction in a communicative context. New York: Taylor \& Francis. Doi: 10.4324/9780203850961

[30] Panova, I. \& R. Lyster (2002). Patterns of corrective feedback and uptake in an adult ESL classroom. TESOL Quarterly 36.4, 573-595

[31] Prabhu, N. S. (1987). Second language pedagogy. Oxford University Press.

[32] Rassaei, E., Moinzadeh, A., \& Youhannaee, M. (2012). Effects of recasts and metalinguistic corrective feedback on the acquisition of implicit and explicit L2 knowledge. The Journal of Language Teaching and Learning, 2(1), 59-75.

[33] Russell, J. \& Spada, N. (2006). The effectiveness of corrective feedback for second language acquisition: A meta-analysis of the research. In J. Norris \& L. Ortega (Eds.), Synthesizing research on language learning and teaching, 133-164. Amsterdam/Philadelphia: John Benjamins.

[34] Schmidt, R. (1990). The role of consciousness in second language learning. Applied Linguistics, 11(2), 129-158.

[35] Schmidt, R. (2001). Attention. In P. Robinson (Ed.), Cognition and second language instruction (pp. 3-32). NY: Cambridge University Press.

[36] Selinker L (1972). Interlanguage. IRAL 10, 209-231.

[37] Sheen, Y. (2004). Corrective feedback and learner uptake in communicative classrooms across instructional settings. Language Teaching Research, 8,263-300.

[38] Sheen, Y. (2006). Exploring the relationship between characteristics of recasts and learner uptake. Language Teaching Research, 10(4), 361-392.

[39] Swain, M. (1985). Communicative competence: some roles of comprehensible input and comprehensible output in its development. In S. M. Gass \& Madden C. D. (Eds.), Input in second language acquisition (pp. 235- 253). Rowley, MA: Newbury House.

[40] Truscott, J. (1996). The case against grammar correction in L2 writing classes. Language Learning, 46, 327-369.

[41] Truscott, J. (1998). Noticing in second language acquisition: A critical review. Second Language Research, 14(2), $103-135$.

[42] Truscott, J. (1999). The case for "the case for grammar correction in L2 writing classes": A response to Ferris. Journal of Second Language Writing, 8, 111-122.

[43] Truscott, J. (2007). The effect of error correction on learners' ability to write accurately. Journal of Second Language Writing, 16, 255-272

[44] VanPatten, B. (1990). Attending to form and content in the input. Studies in second language acquisition, 12(03), $287-301$.

[45] VanPatten, B. \& Cadierno, T. (1993). Explicit instruction and input processing. Studies in Second Language Acquisition, 15, 225-243

[46] Yang, Y., \& Lyster, R. (2010). Effects of form-focused practice and feedback on Chinese EFL learners' acquisition of regular and irregular past tense forms. Studies in Second Language Acquisition, 32(2), 235-263. 


\section{Appendix A: The Oral Test}

\section{Background}

Age:

Gender: $\square$ Male $\quad \square$ Female

Mother tongue:

Other languages:

\section{Consonantal segments}

\begin{tabular}{|ll|ll|lc|l|}
\hline 1) & Chasm & $6)$ & Psychology & 11) & Glisten & 6) Cheap \\
2) & Chorus & $7)$ & Subtle & $12)$ & Three & 17) Hiccough \\
$3)$ & Schism & $8)$ & Singer & $13)$ & That & 18) Tough \\
$4)$ & Archive & $9)$ & Bomb & $14)$ & Aisle & 19) Transmit \\
5) & Hierarchy & $10)$ & Ringing & $15)$ & Plumber & 20) Secondary \\
\hline
\end{tabular}

\section{Vocalic segments}

\begin{tabular}{|ll|l|l|l|}
\hline 1) & Relative & 6) Leave & 11) Information & 16) May \\
2) & Wilderness & 7) Bitten & 12) Rhetoric & 17) Determine \\
$3)$ & Live & 8) Rumor & 13) Position & 18) Foci \\
$4)$ & Family & 9) Superior & 14) Petition & 19) Online \\
5) & Women & 10) Delete & 15) Follow & 20) Pupil \\
\hline
\end{tabular}

\section{Suprasegmental}

\begin{tabular}{l|l|l|l}
\hline 1) To present & 6) Record & 11) Democracy & 16) Blackbird \\
2) To digest & 7) Content & 12) Dependability & 17) Greenhouse \\
3) To permit & 8) Present & 13) Photography & 18) Bad-tempered \\
4) To convict & 9) Surreal & 14) Geology & 19) Understand \\
5) To separate & 10) About & 15) Geologic & 20) Overflow \\
\hline
\end{tabular}

\section{Appendix B: List of Tables}

Table 1: The demographic profile of the participants in the experiment

\begin{tabular}{cccccc}
\hline \multirow{2}{*}{ Gender and age } & \multicolumn{2}{c}{ Gender } & & \multicolumn{2}{c}{ Age } \\
& Male & Female & $18-20$ & $21-25$ & $26-30$ \\
$\mathrm{~N}$ & 12 & 18 & 10 & 19 & 1 \\
\hline
\end{tabular}


Table 2: The comparison between the prompt and the recast groups

\begin{tabular}{cccccc}
\hline & Sum of Squares & df & Mean Square & $F$ & Sig. \\
\hline Between Groups & 4062.067 & 2 & 2031.033 & 165.523 & .000 \\
Within Groups & 331.300 & 27 & 12.270 & & \\
Total & 4393.367 & 29 & & \\
\hline
\end{tabular}

Table 3: Tukey HSD on multiple comparisons

\begin{tabular}{|c|c|c|c|c|c|c|}
\hline \multirow[b]{2}{*}{ (I) Groups } & \multirow[b]{2}{*}{ (J) Groups } & \multicolumn{2}{|l|}{ Mean Difference } & \multirow[b]{2}{*}{ Sig. } & \multicolumn{2}{|c|}{ 95\% Confidence Interval } \\
\hline & & $(I-J)$ & Std. Error & & Lower Bound & Upper Bound \\
\hline \multirow[t]{2}{*}{ Control } & Prompt & $-13.90^{*}$ & 1.567 & .000 & -17.78 & -10.02 \\
\hline & Recast & $-28.50^{*}$ & 1.567 & .000 & -32.38 & -24.62 \\
\hline \multirow[t]{2}{*}{ Recast } & Control & $13.90^{*}$ & 1.567 & .000 & 10.02 & 17.78 \\
\hline & Prompt & $-14.60^{*}$ & 1.567 & .000 & -18.48 & -10.72 \\
\hline \multirow[t]{2}{*}{ Prompt } & Control & $28.50^{*}$ & 1.567 & .000 & 24.62 & 32.38 \\
\hline & Recast & $14.60^{*}$ & 1.567 & .000 & 10.72 & 18.48 \\
\hline
\end{tabular}

Based on observed means.

The error term is Mean Square(Error) $=12.270$.

*. The mean difference is significant at the .05 level. 